\title{
How to prevent skin damage from air pollution. Part 1: Exposure assessment
}

\author{
Katerina Damevska ${ }^{1}$ (0) | Blazo Boev ${ }^{2}$ | Dejan Mirakovski ${ }^{2}$ | Andrej Petrov ${ }^{3,4}$ | \\ Razvigor Darlenski ${ }^{5,6}$ | Viktor Simeonovski ${ }^{1}$
}

\author{
${ }^{1}$ University Clinic of Dermatology, Medical \\ Faculty, Ss Cyril and Methodius University, \\ Skopje, Macedonia \\ ${ }^{2}$ Faculty of Natural and Technical Science, \\ Goce Delcev University, Macedonia \\ AMBICON Lab, Stip, Macedonia \\ ${ }^{3}$ Faculty of Medical Sciences, Goce Delcev \\ University, Stip, Macedonia \\ ${ }^{4}$ Acibadem Sistina Clinical Hospital, Skopje, \\ Macedonia \\ ${ }^{5}$ Department of Dermatology and \\ Venereology, Trakia University, Stara Zagora, \\ Bulgaria \\ ${ }^{6}$ Acibadem City Clinic Tokuda Hospital, Sofia, \\ Bulgaria

\section{Correspondence} \\ Katerina Damevska, University Clinic of \\ Dermatology, Medical Faculty, Ss Cyril and \\ Methodius University, Bul Majka Teresa \\ 18, 1000 Skopje, Macedonia. \\ Email: kate_damevska@yahoo.com
}

\begin{abstract}
Both epidemiological and experimental studies have demonstrated the crucial connection between air pollution exposure and skin disorders. The exact mechanisms by which air pollutants mediate skin damage remain largely unknown. Therefore, it is very necessary to investigate the mechanism of air pollution-induced skin damage and explore some potential protective and therapeutic methods. In this review, we focus on the qualitative and quantitative skin exposure assessment methodologies-a relatively new field of interdisciplinary research.
\end{abstract}

\section{KEYWORDS}

air pollution, exposure assessment, skin

\section{1 | INTRODUCTION}

Nine out of ten people are exposed to polluted air every day (WHO, 2019). In 2019, air pollution (AP) is considered by WHO as the biggest environmental health risk, responsible for killing 7 million people prematurely every year. Around $90 \%$ of these deaths are in low- and middleincome countries (WHO, 2019), where population explosion along with widespread industrialization and huge social disparities resulted in dense urban centers with poor air quality (Mannucci \& Franchini, 2017).

To date, air pollution-both ambient (outdoor) and household (indoor) is involved in cardiovascular and pulmonary diseases (WHO, 2019), neurodevelopmental and neurodegenerative disorders (ChinChan, Navarro-Yepes, \& Quintanilla-Vega, 2015), altered fertility and adverse gestational outcomes (Carré, Gatimel, Moreau, Parinaud, \& Léandri, 2017).

Recent studies suggest that certain dermatological disorders, such as atopic dermatitis (AD), premature skin aging, acne, and skin cancer, among others, are strongly associated with environmental pollution (Ngoc, Park, Lee, \& Lee, 2017). Aggravation of AD by aeroallergens is a remarkable example and an in vivo model of interactions between host- and environment-related factors (Kim et al., 2017).

The present understanding of the impact of ambient AP on skin health is incomplete. With the exception of a few hazardous substances, data on skin exposure of the majority of air pollutants is limited. Individual pollutants may be implicated in a wide range of effects, whereas few diseases are directly attributable to single pollutants (chloracne caused by halogenated aromatic compounds). In addition, exposures may occur via a range of pathways, and the combined effects of two or more pollutants may be more severe or even qualitatively different from the individual effects of separate pollutants (Damevska, Nikolovska, Kazandjieva, Trifunova, \& Bocheva, 2019; Oresajo, Pillai, Manco, Yatskayer, \& McDaniel, 2012). Similarly, dermatological hazards can be amplified by the possible synergy between AP and sun exposure, especially UVA (Marrot, 2018). These characteristics can complicate modeling and other analyses aimed at risk assessment and exposure management.

In this review, we summarize the methods used to examine these important research questions. The second part of the review, to be 
published later, will concentrate on the evidence supporting exposure to air pollution as a risk for skin damage, as well as on current prevention and treatment options.

\section{I SOURCES AND COMPOSITION OF AIR POLLUTION}

Air pollution (AP) is the contamination of outdoor and indoor environments by any chemical, physical, or biological agent that modifies the natural characteristics of the atmosphere (WHO, 2019). Pollutants can be naturally occurring substances or energies, or xenobiotics to which organisms have not adjusted through prior evolution. Air pollutants may have a natural (biogenic), anthropogenic, or mixed origin.

Primary pollutants are substances directly emitted from a process; Key primary air pollutants include particulate matter (PM), black carbon, sulfur oxides, nitrogen oxides (NOx), carbon monoxide (CO), volatile organic compounds (VOCs), and certain metals. Secondary pollutants are formed in the atmosphere from precursor pollutants through reactions. Key secondary air pollutants are secondary particulate matter (also called secondary inorganic aerosols), ozone, and a number of oxidized VOCs. Table 1 presents major air pollutants and their sources (IARC, 2013; Magnani et al., 2016).

Particle pollution is a complex mixture of extremely small particles and liquid droplets. These particles come in many sizes and shapes and can be made up of a number of components, including soil or dust particles, acids, organic chemicals, and metals (U.S. EPA, 2017). Based on their size, these particles are divided into three major categories: PM2.5 (diameter of particle $\leq 2.5 \mu \mathrm{m})$, PM10 $(2.5-10 \mu \mathrm{m})$, and PM0.1- ultrafine particles $(\leq 0.1 \mu \mathrm{m})$.

The EPA has designated six criteria pollutants that are routinely monitored: PM, ground-level ozone, sulfur dioxide $\left(\mathrm{SO}_{2}\right)$, lead, $\mathrm{CO}$, and $\mathrm{NOx}$, which includes nitric oxide (NO), nitrogen dioxide $\left(\mathrm{NO}_{2}\right)$, and nitrous oxide $\left(\mathrm{N}_{2} \mathrm{O}\right)$. Criteria pollutants are found in relatively high concentrations, while hazardous air pollutants are chemical compounds that are found in trace concentrations but may cause serious health effects.

\subsection{Urban air pollution}

Urban regions have over $50 \%$ of the world's population and this proportion will increase to $70 \%$ by 2050 (U.N., 2014). Recent evidence, derived mainly from epidemiologic studies, indicate that urban AP causes a wide range of effects on human health (Cho et al., 2018).

Urban AP results from the complex interaction of multiple emissions and chemical reactions. Domestic fuel burning dominates the contributions to urban AP in many developing countries (Mannucci \& Franchini, 2017; Mirakovski et al., 2018), with significant differences between sources and composition in different cities. In addition, human exposures to AP in urban areas vary greatly due to spatiotemporal variations in emissions, varying proximity to sources, atmospheric circulation, and local meteorological conditions. Thus, the term "urban air pollution" can refer to very different exposure mixtures (Cho et al., 2018).

\section{2 | Traffic-related air pollution}

Traffic-related air pollution (TRAP) is a major source of ambient air pollution in urban areas, especially in urban centers along roadsides and in urban street canyons.

The gaseous and particulate pollutants to which motor vehicles contribute include, but are not limited to NOx, CO, ozone, and PM0.1. The Health Effects Institute (HEI, 2010) identified that an exposure zone within a range of up to $300-500 \mathrm{~m}$ from high-traffic roads as the area most highly affected by traffic emissions. Hence, living near major roads was the primary exposure variable in many of the epidemiological studies on health effects caused by air pollution to the skin. However, the contribution of traffic to personal exposure to air

TAB LE 1 Major air pollutants, their physical state, and sources

\begin{tabular}{|c|c|c|}
\hline Pollutant/pollutant class & Physical state & Major sources \\
\hline Ozone & Gas & Generated from $\mathrm{NO}_{x}, \mathrm{VOCs}$, and $\mathrm{CO}$, as well as natural processes \\
\hline Sulfur dioxide $\left(\mathrm{SO}_{2}\right)$ & Gas & Fossil fuel combustion, natural emissions \\
\hline Carbon monoxide (CO) & Gas & $\begin{array}{l}\text { Fossil fuel combustion, oxidation of biogenic, oxidation of volatile } \\
\text { organic compounds (VOCs) emissions }\end{array}$ \\
\hline Nitrogen oxides $\left(\mathrm{NO}_{x}\right)$ & Gas & Combustion processes \\
\hline $\begin{array}{l}\text { Hazardous air pollutants (benzene, } \\
\text { 1,3-butadiene, formaldehyde, acids) }\end{array}$ & Gas & Incomplete combustion, chemical processing, solvent use \\
\hline Mercury (Hg) & Gas and particulate & Coal combustion, ore refining, natural \\
\hline Lead $(\mathrm{Pb})$ & Particulate & Leaded fuel combustion, lead processing \\
\hline $\begin{array}{l}\text { PM, including } \mathrm{PM}_{2.5}, \mathrm{PM}_{10} \text {, inhalable PM, } \\
\text { total suspended particles (TSP) }\end{array}$ & Particulate (condensed phase) & $\begin{array}{l}\text { Dust storms, fossil fuel combustion, biomass fuel combustion, } \\
\text { biogenic emissions, fertilizer use, gas-to-particle conversion }\end{array}$ \\
\hline Organic carbon $(\mathrm{OC})$ & Particulate & $\begin{array}{l}\text { Fossil and biomass fuel combustion, vegetative detritus, oxidation } \\
\text { of gaseous organic compounds }\end{array}$ \\
\hline
\end{tabular}

Note: According to IARC Working Group on the Evaluation of Carcinogenic Risk to Humans (IARC, 2013) and Magnani et al. (2016). 
pollution is difficult to quantify with traditional epidemiological approaches (Adar \& Kaufman, 2007).

Over recent decades, in most cities in North America and Europe air quality has significantly improved; emissions of the leading old air pollutants such as $\mathrm{SO}_{2}$, lead, and heavy metals have declined significantly. At present, ground-level ozone, airborne PM, and polycyclic aromatic hydrocarbons (PAHs) are the new problematic pollutants in large urban agglomerations (Ferrante et al., 2012).

\section{3 | Aeroallergens}

Aeroallergens are various airborne antigens, usually proteinaceous in nature, that sensitize the host for allergic reactions and for the production of allergen-specific IgE. Their sources are diverse and include house dust, mite products, pollens, fungal spores, animals, drugs, and foods.

Airborne allergens are not present as single molecules in the gas phase, but components of certain particles such as pollen grains or mold spores, or adsorbed to and carried on inorganic or organic dust particles. Oxidation of the organic compounds and the condensation of oxygenated organics may lead to the enrichment of mineral dust with surface-active polar organics. The adsorption of low-vaporpressure organic species on mineral dust may be a key process that affects their long-range transport (Cecchi, D'Amato, \& AnnesiMaesano, 2018).

Several properties of allergens, including the integrity of the allergenic protein, binding capacity, resistance to degradation, proteolytic function and mimicry of the allergen with endogenous proteins facilitate barrier disruption and skin sensitization (Pomés, 2002). As a consequence, early exposure to aeroallergens through the skin may be a risk factor for allergic sensitization. However, the mechanisms of cutaneous penetration of allergens, sensitization, and the development of allergic disease are likely much more complex than previously assumed (Knaysi, Smith, Wilson, \& Wisniewski, 2017).

Air pollutants can modify allergenic proteins, thus affecting their interactions with the immune system. Increased allergenicity was observed in different types of pollens when exposed to $\mathrm{NO}_{2}$ (Carlsten et al., 2016). Although pollen is a well-known risk factor for respiratory allergy, its role in the development or exacerbation of skin allergic diseases is still to be fully elucidated.

\section{3 | THE EXPOSOME OF HUMAN SKIN}

To emphasize the importance of more complete evaluation of environmental exposure, the term exposome was coined by the British cancer epidemiologist Christopher Wild (2005).

Exposome refers to the entirety of external environmental exposures to which a subject is exposed from preconception onward, and the biological response to the external domain. The exposome can be viewed as the environmental equivalent of the human genome (Miller, 2014). Study of the exposome relies on the measurement of external exposures (direct measurements and survey instruments), and internal exposures (biomarkers of endogenous processes).

The greatest challenge in exposome-based studies is the need to collect and analyze large data sets. This data can also be difficult to interpret across multiple spatial and temporal scales.

The definition of the exposome continues to evolve, along with new technologies and analytic methods grounded within informatics and data science disciplines.

The implementation of the exposome approach in dermatology has started only recently. The overall aim of this approach is to assess the combined and cumulative effects of AP on skin health, using a total environmental framework (natural and social environments, personal characteristics and behaviors' activities) over time and space.

Krutmann's research team (Krutmann, Bouloc, Sore, Bernard, \& Passeron, 2017) proposed the following as the major environmental factors associated with skin aging: solar radiation, atmospheric pollution, tobacco smoke, nutrition, and cosmetic products. This innovative concept was also implemented by Dréno, Bettoli, Araviiskaia, Sanchez Viera, and Bouloc (2018); in the example of acne, this would mean accurate assessment of nutrition, medication, occupational factors, pollutants, climatic and lifestyle factors.

We strongly believe that the exposomic approach is particularly applicable to skin diseases. As an exposed organ, skin provides the opportunity to link exposure to specific biological responses. For example, a specific air pollutant with known chemical and physical characteristics may induce measurable skin changes (e.g., transepidermal water loss-TEWL) as well as a biological response (e.g., antioxidant system activation) and a biological impact of the exposure (e.g., DNA damage).

\section{4 | DERMAL EXPOSURE ROUTE}

Environmental medicine has traditionally focused on the inhalation exposure pathway because it is seen as the most important route of exposure (Schneider et al., 1999); dermal absorption and its permeation mechanisms of both particulate and gaseous contaminants through air-to-skin transport have been largely overlooked ( $\mathrm{Wu}, \mathrm{Bao}$, Tao, \& Zeng, 2016).

Uptake via inhalation or via the dermal pathways follows different mechanisms. Uptake by inhalation depends largely on the alveolar concentration of inhalation agents, and on diffusion and solubility (blood-gas partition coefficient), while dermal uptake depends on the deposition of the hazardous substances on the skin surface, the composition physical properties of epidermal lipids, and the diffusion through the epidermis to the blood vessels (Krais et al., 2018).

There are two options for substances to permeate the stratum corneum (SC): transepidermal and diffusion through hair follicles and sweat ducts. The transepidermal route can be divided into the transcellular and the intercellular route. Diffusion through hair follicles and sweat ducts is the shortest route, but the substances encounter significant resistance to permeation because they need to penetrate both lipophilic and hydrophilic structures. Despite the fact that skin 
appendages occupy only $0.1 \%$ of the total skin surface, they are important vertical pathways for percutaneous penetration (Trommer \& Neubert, 2006).

Dermal absorption from airborne compounds has only recently attracted more attention. Pesticides, solvents, and mercury, isocyanates, polychlorinated biphenyls, acrylates, and polycyclic aromatic hydrocarbons (PAHs) are some of the main chemical groups that have been recognized as posing health problems by dermal absorption (Semple, 2004).

Several studies have assessed the contributions of dermal absorption to the total concentrations of selected chemicals. Concentrations of urinary metabolites due to dermal uptake from 2-butoxyethanol, were roughly equal to or even greater than those from inhalation exposure (Kezic, Meuling, \& Jakasa, 2004).

Weschler et al. (2015) performed a series of experiments with bare-skin participants who were exposed to diethyl phthalate, via inhalation and skin. Equal levels of excreted metabolites were found after inhalation $\left(3.8 \mu \mathrm{g} / \mu \mathrm{g} / \mathrm{m}^{3}\right)$ and dermal exposure $(4.0 \mu \mathrm{g} /$ $\left.\mu \mathrm{g} / \mathrm{m}^{3}\right)$. These results clearly indicate the importance of dermal absorption.

In addition, several occupational studies have quantified heavy metals skin exposure. In a Swedish study, blood has been used as a biomarker for skin exposure of cobalt; despite low measured air concentrations, monitoring of cobalt in blood shows relatively high concentrations, confirming the role of dermal absorption (Klasson et al., 2017).

\section{1 | Role of exposure and dose}

The best approach to manage the health hazards associated with exposure (and subsequent absorption) of the skin to air pollutants, is to identify relevant pollutants, sources, and pathways of exposure, and quantitatively assess the exposure (WHO, 2014). Methods for estimating skin exposure require information on the exposed surface area, and on factors that may affect the loading of chemicals on the skin (U.S. EPA, 2011).

The terms "exposure" and "dose" are closely linked, and often confused (Zartarian, Ott, \& Duan, 2007). Exposure does not necessarily lead to a dose. The exposure becomes an absorbed dose (also known as bioavailable dose) when the agent crosses a specific absorption barrier.

\subsection{Adherence of solids to skin}

The adhesion of solid particles to the skin surface is a complex process influenced by particle size, soil type, anatomical localization, and soil and skin moisture (Driver, Konz, \& Whitmyre, 1989; Ferguson, Biddle, Coleman, Bursac, \& Johnson, 2009). The adherence factor describes the amount of solid material that adheres to the skin per unit of surface area (U.S. EPA, 2011). Ferguson and coworkers conducted experiments on the transfer of soil to human skin during multiple contacts and noted that a second contact added an additional $8 \%$ of the soil to the skin (Ferguson et al., 2009).

\subsection{In vitro and in vivo models}

Several studies attempted to develop clinically relevant in vitro and in vivo models that mimic skin exposure to various pollutants to gain more detailed insights into mechanisms associated with skin damage, as well as therapeutic strategies.

The SKH-1 hairless mouse is used to study the effects of ozone exposure on skin. Exposure to increasing doses of ozone resulted in a dose-dependent depletion of vitamin $\mathrm{C}$ and $\mathrm{E}$, cumulative oxidative damage to the stratum corneum (Thiele, Traber, Polefka, Cross, \& Packer, 1997). Furthermore, topical application of antioxidants attenuates oxidative stress in mouse skin (Thiele, Traber, Podda, et al., 1997). Afaq et al. (2009) showed that normal human epidermal keratinocytes exposure to ozone led to aryl hydrocarbon receptor (AhR) nuclear translocation and increased AhR mRNA expression, suggesting that there are toxicological consequences of ozone to human skin.

\section{5 | ASSESSMENT OF SKIN EXPOSURE TO AIR POLLUTION}

Krutmann et al. (2014) suggest that each individual air pollutant has most probably a specific, toxic action on the skin. Therefore, evidence for exposure to specific pollutants is fundamental for assessing its biological effects.

Air pollution exposure assessment faces several important challenges: (a) intensity of exposure is rarely constant over space or time, (b) the agents are diverse and complex, (c) exposure includes a behavioral component that is also complex and variable, and (d) people respond differently to exposures, so effects are often seen in a small number of individuals (Savitz 2003).

The skin air-mediated exposure, similar to inhalation, occurs constantly (Wu et al., 2016). Compared to inhalation exposure, it is less clear how the measured levels of skin exposure should be interpreted. For example, air pollutants are separated from perfused skin tissue by the SC, which acts as a rate-limiting barrier having a certain buffer capacity.

A conceptual source-receptor model proposed by Schneider et al. (1999) describes dermal uptake as a result of transport of mass between compartments, driven by the concentration gradient. Some of the basic phases of transport processes are (a) deposition of substances from the air to the skin contaminant layer, (b) resuspension or evaporation of substances from the skin contaminant layer to the air, and (c) penetration and permeation, which both involve transport of substances through the rate-limiting SC. Particles complicate the concept of concentration since they are discrete entities; uptake can be limited by the rate of dissolution and not by the diffusion through the SC (Schneider et al., 1999). 
Dermal absorption of gas-phase chemicals directly from the air can make a significant contribution to the total intake of an airborne pollutant and should be also included in aggregate exposure (Rauma, Boman, \& Johanson, 2013).

Gong, Zhang, and Weschler (2014) developed a transient model to estimate the transport of a gas-phase organic compound from the air through the skin to blood, as a function of time for different exposure scenarios. This model considers convective mass-transfer resistance through the boundary layer of air adjacent to the skin surface, as well as through the SC and viable epidermis. Sensitivity analysis shows that the absorption flux into blood tends to be more sensitive to the SC thickness and effective diffusion coefficient in SC than the other parameters. Morrison, Weschler, and Bekö (2016) modified the transient model to a dynamic model, which include surface lipids as a layer distinct from the underlying SC, as well as the impact of clothing.

Taken together, these models have implications for the efficacy of bathing in terms of exposure to selected VOCs via the dermal pathway. Several studies have shown that bathing removes chemicals compounds with high lipophilicity and high molecular weight such as phthalates, well known as endocrine disruptors (Gong et al., 2014; Lin et al., 2017).

\section{1 | Factors that influence skin absorption of air pollutants}

Several factors can influence skin absorption of air pollutants. These include (U.S. EPA, 1992; WHO, 2014):

- The concentration of the substance contacting a given area of skin (dermal loading or skin adherence).

- The ability of the chemical to penetrate and pass through intact skin (dermal dose).

- The site of the exposure (regional variation in skin permeability in different body sites).
- Individual variability of skin penetrability due to age, sex, and skin integrity.

- Skin surface pH, corneal layer hydration, desquamation, sweat, and sebum production.

- Reduction or increase in the chemical contact with the skin due to clothing.

- The matrix (liquid, solid, vapor) of the contaminant.

- External characteristics (temperature, humidity, the presence of other pollutants).

- Duration and frequency of contact.

\subsection{Exposure assessment}

Exposure assessment methods were developed primarily for the assessment of occupational exposure to chemicals, and only a few studies are available for selected hazardous air pollutants (Gong et al., 2014; Krais et al., 2018; Morrison et al., 2016; Weschler et al., 2015).

These include both direct and indirect approaches (Table 2). The direct methods are further subdivided into three groups: (a) interception (formerly surrogate skin) techniques; (b) removal techniques; and (c) in situ techniques (WHO, 2014). A further distinction that may be made is between quantitative methods that rely on numerical scores and qualitative methods. The quantitative assessment of dermal exposure is in many instances less straightforward than the quantitative assessment of inhalation exposure (Boogaard, 2008).

Each method bears special advantages and disadvantages related to its general applicability, accuracy, or reliability. Nonetheless, there is a lack of method-comparison studies (WHO, 2014).

The interception techniques involve the use of whole-body dosimeters or patches (clothing), which collect all mass deposited in a given time on a given area. It is important to consider that this approach is the only one that prevents penetration of the substance into deeper skin layers. Examples of interception methods include

TAB LE 2 Sampling techniques for direct measurements of skin exposure (Adapted from WHO, 2014)

\begin{tabular}{|c|c|c|}
\hline Method & Principle of sampling & Examples \\
\hline In situ techniques & $\begin{array}{l}\text { In situ techniques use the spectroscopic properties of } \\
\text { either the substance itself or a tracer mixed with the } \\
\text { substance. }\end{array}$ & $\begin{array}{l}\text { Assessment of dermal pesticide exposure with fluorescent } \\
\text { tracer. } \\
\text { Light sensor technique for detection of coal contamination } \\
\text { on the skin. }\end{array}$ \\
\hline Wiping technique & $\begin{array}{l}\text { Defined surface of the skin is wiped with moist or soaked } \\
\text { sampling media, (cotton, filter paper, sponges, surgical } \\
\text { swabs). }\end{array}$ & $\begin{array}{l}\text { Cellulose wipes soaked with a } 1 \% \text { solution of nitric acid for } \\
\text { nickel, chromium, and cobalt sampling. }\end{array}$ \\
\hline Suction method & Sampling by the application of a vacuum & $\begin{array}{l}\text { Solid phase (i.e., powders or particulates), radioactive } \\
\text { contamination, lead contamination, allergenic particles } \\
\text { (Byrne, 2000) }\end{array}$ \\
\hline Tape stripping technique & $\begin{array}{l}\text { The technique is based on the gradual removal of the SC, } \\
\text { including the substances deposited in this layer. }\end{array}$ & $\begin{array}{l}\text { Adherent substances, such as particles or viscous } \\
\text { substances. } \\
\text { 1,6-hexamethylene diisocyanate (Thomasen et al., 2011) }\end{array}$ \\
\hline Washing & $\begin{array}{l}\text { Washing with water or solvents. Solvents influence the } \\
\text { characteristics of the skin. }\end{array}$ & Pesticides (Fenske et al., 1998) \\
\hline
\end{tabular}


gloves, and exposure patches (cotton, polymer, paper, charcoal cloth or composite materials), which serve as surrogates for the skin for collecting deposited substances (Thomasen, Fent, \& NylanderFrench, 2011).

Removal techniques include wiping, handwashing, tape stripping, suction, and immersion methods. Depending on the chemical nature of the measured compound, different solvents can be used (deionized water, pure alcohols, or mixtures of them).

The sampling efficiency of the handwash technique has been found to depend on the washing solution, duration of exposure, prewashing of the hands, skin loading levels and number of washings (Fenske, Schulter, Lu, \& Allen, 1998).

Suction sampling of skin is limited to sampling materials with low adhesion forces, such as solid particles. Particulate removed in suction sampling represents a fraction of the amount which is present in the skin contaminant layer at a given time (Byrne, 2000).

The tape stripping technique is based on the removal of the stratum corneum (SC), including the substances deposited in this layer. The tape strip is applied under pressure and forms a tight mechanical bond with the SC, and subsequently removed by taking off the strip.

In situ techniques use the spectroscopic properties of substances, or a tracer mixed with the substance. Fluorescent tracers allow qualitative or semiquantitative exposure assessment by observation and thus identification of the contaminated body parts.

At present, the most commonly used in situ techniques are video imaging technique (suitable for measurements on large surfaces), Fourier transform infrared spectroscopy with attenuated total reflectance (ATR-FTIR technique), and detection via a light sensor. Video imaging is applied mainly for semiquantitative or qualitative measurements (WHO, 2014).

\section{3 | Biomonitoring}

Biomonitoring, defined as systematic standardized measurement of concentration of a substance or its metabolites in human tissues (such as blood, urine, milk) has become an important tool in evaluating exposure to air pollutants. There are several different categories of biomarkers that measure exposure, effect, and susceptibility. One advantage of biomonitoring is that it gives a direct indication of internal dose, and it reflects cumulative exposure from all exposure routes (inhalation, dermal, and oral). However, it should be noted that biomonitoring by itself does not provide information on the source or route of exposure (WHO, 2014).

Use of biomonitoring data in a context of AP requires consideration of many factors, including differential toxicokinetic properties of certain air pollutants. The presence of a chemical in the biological samples does not itself mean that the chemical will cause harm. The concentration of a chemical detected in the body needs to be compared to concentrations known to cause health effects (Arnold et al., 2013).

Most of the data on exposure markers are related to occupational environments. Biological markers for acute exposure to $\mathrm{CO}$ (carboxyhemoglobin in serum), trichloroethylene (trichloroacetic acid in urine), and organophosphates (cholinesterase in serum) are widely used. Biological tests for metals such as lead, cadmium, arsenic, mercury, selenium, tellurium, manganese, thallium, and zinc are also well established (WHO, 2014).

Several investigators have attempted to demonstrate the role of skin absorption as a route of AP exposure including blood cobalt levels in hard metal-production workers (Klasson et al., 2017), urinary PAH metabolites as exposure biomarkers (Li et al., 2016) and plasma levels of phthalates (Weschler et al., 2015).

Research is required to better define the dose and skin exposure and dose and health outcome relationships. Exposome-Explorer is the first database on biomarkers of exposure with detailed information on their concentrations in various human biospecimens, and correlations with external exposure measurements (Neveu et al., 2017).

The appeal of using biomonitoring for assessing pollution exposure is somewhat overshadowed by the need to apply invasive methods of tissue sampling to obtain sufficient material for bioanalytical evaluation. Further developments in methodology are needed to accelerate the breakthroughs in this field. In this direction, Cooke, Hu, Chang, and Chao (2018) developed a novel approach in exposomics, presenting a method for adductomic approach of human biomonitoring by applying adductomics to urinary DNA samples.

\section{6 | CONCLUSION}

Both epidemiological and experimental studies have demonstrated the crucial connection between AP exposure and skin disorders. However, our knowledge regarding the effects of AP on skin, currently, remains limited. Most of the published exposure studies are focused only on a small group of pollutants.

There is a strong need for further research exploring potential mechanisms underlying these relationships. Assessment of skin exposure to AP is a fundamental component of this process. Therefore, not only a vast understanding of the already known methods of skin exposure assessment is needed, but also new interdisciplinary approaches and innovative ideas are necessary for the future development of a relatively new interdisciplinary field. This is an important step to greatly facilitate the development of novel therapeutic and preventive strategies.

Future studies should address some of the limitations to the methods presented in this review. Last, due to paucity of scientific evidence, there are no established guidelines currently available for protecting the skin against air pollution. Aside from reducing exposure, potential protection strategies should focus on repairing the skin barrier, replenishing antioxidant reserve, and reducing inflammation caused by air pollutants. Formulating of novel protective compounds and subsequently cosmetic products would be an ultimate outcome from this kind of research for the benefit of the population. 


\section{CONFLICT OF INTEREST}

The authors declare no potential conflict of interest.

\section{ORCID}

Katerina Damevska (D) https://orcid.org/0000-0003-4745-3747

\section{REFERENCES}

Adar, S. D., \& Kaufman, J. D. (2007). Cardiovascular disease and air pollutants: Evaluating and improving epidemiological data implicating traffic exposure. Inhalation Toxicology, 19(Suppl. 1), 135-149.

Afaq, F., Zaid, M. A., Pelle, E., Khan, N., Syed, D. N., Matsui, M. S., ... Mukhtar, H. (2009). Aryl hydrocarbon receptor is an ozone sensor in human skin. Journal of Investigative Dermatology, 129(10), 2396-2403.

Arnold, S. M., Angerer, J., Boogaard, P. J., Hughes, M. F., O'Lone, R. B., Robison, S. H., \& Schnatter, A. R. (2013). The use of biomonitoring data in exposure and human health risk assessment: Benzene case study. Critical Reviews in Toxicology, 43(2), 119-153.

Boogaard, P. J. (2008). Getting under the skin. Human and Experimental Toxicology, 27(4), 267-268.

Byrne, M. A. (2000). Suction methods for assessing contamination on surfaces. Annals of Occupational Hygiene, 44(7), 523-528.

Carlsten, C., Blomberg, A., Pui, M., Sandstrom, T., Wong, S. W., Alexis, N., \& Hirota, J. (2016). Diesel exhaust augments allergeninduced lower airway inflammation in allergic individuals: A controlled human exposure study. Thorax, 71(1), 35-44.

Carré, J., Gatimel, N., Moreau, J., Parinaud, J., \& Léandri, R. (2017). Does air pollution play a role in infertility?: A systematic review. Environmental Health, 16(1), 82

Cecchi, L., D'Amato, G., \& Annesi-Maesano, I. (2018). External exposome and allergic respiratory and skin diseases. The Journal of Allergy and Clinical Immunology, 141(3), 846-857.

Chin-Chan, M., Navarro-Yepes, J., \& Quintanilla-Vega, B. (2015). Environmental pollutants as risk factors for neurodegenerative disorders: Alzheimer and Parkinson diseases. Frontiers in Cellular Neuroscience, 9, 124.

Cho, C. C., Hsieh, W. Y., Tsai, C. H., Chen, C. Y., Chang, H. F., \& Lin, C. S. (2018). In vitro and in vivo experimental studies of PM2.5 on disease progression. International Journal of Environmental Research and Public Health, 15(7), 1380.

Cooke, M. S., Hu, C. W., Chang, Y. J., \& Chao, M. R. (2018). Urinary DNA adductomics - a novel approach for exposomics. Environment International, 121(Pt 2), 1033-1038.

Damevska, K., Nikolovska, S., Kazandjieva, J., Trifunova, B. K., \& Bocheva, G. (2019). Skin and pollution. In: K. França \& T. Lotti (Eds.), Advances in integrative dermatology (pp. 379-392). New York: John Wiley \& Sons, Inc..

Dréno, B., Bettoli, V., Araviiskaia, E., Sanchez Viera, M., \& Bouloc, A. (2018). The influence of exposome on acne. Journal of the European Academy of Dermatology and Venereology: JEADV, 32(5), 812-819.

Driver, J. H., Konz, J. J., \& Whitmyre, G. K. (1989). Soil adherence to human skin. Bulletin of Environmental Contamination and Toxicology, 43, 814-820.

Fenske, R. A., Schulter, C., Lu, C., \& Allen, E. H. (1998). Incomplete removal of the pesticide captan from skin by standard handwash exposure assessment procedures. Bulletin of Environmental Contamination and Toxicology, 61(2), 194-201.

Ferguson, A. C., Biddle, D., Coleman, S., Bursac, Z., \& Johnson, W. (2009). In-vitro soil adherence for dermal exposure using a controlled mechanical chamber. Journal of Applied Sciences Research, 5, 232-243.

Ferrante, M., Fiore, M., Oliveri Conti, G., Ledda, C., Fallico, R., \& Sciacca, S. (2012). Old and new air pollutants: An evaluation on thirty years experiences. In B. Haryanto (Ed.), Air pollution - A comprehensive perspective (pp. 3-26). Intech Open: Rijeka, Croatia.
Gong, M., Zhang, Y., \& Weschler, C. J. (2014). Predicting dermal absorption of gas-phase chemicals: Transient model development, evaluation, and application. Indoor Air, 24(3), 292-306.

HEI Panel on the Health Effects of Traffic-Related Air Pollution (HEI). (2010). Traffic related air pollution: A critical review of the literature on emissions, exposure, and health effects. HEI Special Report 17. Health Effects Institute, Boston, MA. Retrieved from https://www.healtheffects.org/system/files/SR17Traffic\% 20Review.pdf

IARC. (2013). IARC monographs on the evaluation of carcinogenic risks to humans. Volume 109. Outdoor air pollution. Lyon: International Agency for Research on Cancer. Retrieved from https://monographs. iarc.fr/wp-content/uploads/2018/06/mono109-F07.pdf

Kezic, S., Meuling, W. J. A., \& Jakasa, I. (2004). Free and total urinary 2-butoxyacetic acid following dermal and inhalation exposure to 2-butoxyethanol in human volunteers. International Archives of Occupational and Environmental Health, 77, 580-586.

Kim, Y. M., Kim, J., Han, Y., Jeon, B. H., Cheong, H. K., \& Ahn, K. (2017). Short-term effects of weather and air pollution on atopic dermatitis symptoms in children: A panel study in Korea. PLoS One, 12(4), e0175229.

Klasson, M., Lindberg, M., Bryngelsson, I. L., Arvidsson, H., Pettersson, C., Husby, B., \& Westberg, H. (2017). Biological monitoring of dermal and air exposure to cobalt at a Swedish hard metal production plant: Does dermal exposure contribute to uptake? Contact Dermatitis, 77(4), 201-207.

Knaysi, G., Smith, A. R., Wilson, J. M., \& Wisniewski, J. A. (2017). The skin as a route of allergen exposure: Part II. Allergens and role of the microbiome and environmental exposures. Current Allergy and Asthma Reports, $17(1), 7$.

Krais, A. M., Andersen, C., Eriksson, A. C., Johnsson, E., Nielsen, J., Pagels, J., ... Wierzbicka, A. (2018). Excretion of urinary metabolites of the phthalate esters DEP and DEHP in 16 volunteers after inhalation and dermal exposure. International Journal of Environmental Research and Public Health, 15(11), 2514.

Krutmann, J., Bouloc, A., Sore, G., Bernard, B. A., \& Passeron, T. (2017). The skin aging exposome. Journal of Dermatological Science, 85(3), 152-161.

Krutmann, J., Liu, W., Li, L., Pan, X., Crawford, M., Sore, G., \& Seite, S. (2014). Pollution and skin: From epidemiological and mechanistic studies to clinical implications. Journal of Dermatological Science, 76(3), 163-168.

Li, Z., Commodore, A., Hartinger, S., Lewin, M., Sjödin, A., Pittman, E., ... Naeher, L. P. (2016). Biomonitoring human exposure to household air pollution and association with self-reported health symptoms - a stove intervention study in Peru. Environment International, 97, 195-203.

Lin, P. D., Wu, C. F., Kou, H. S., Huang, T. Y., Shiea, J., \& Wu, M. T. (2017). Removal of diethylhexyl phthalate from hands by handwashing: Evidence from experimental $\mathrm{N}$-of-1 and crossover designs. Scientific Reports, 7(1), 454.

Magnani, N. D., Muresan, X. M., Belmonte, G., Cervellati, F., Sticozzi, C., Pecorelli, A., ... Valacchi, G. (2016). Skin damage mechanisms related to airborne particulate matter exposure. Toxicological Sciences, 149(1), 227-236.

Mannucci, P. M., \& Franchini, M. (2017). Health effects of ambient air pollution in developing countries. International Journal of Environmental Research and Public Health, 14(9), 1048.

Marrot, L. (2018). Pollution and sun exposure: A deleterious synergy. Mechanisms and opportunities for skin protection. Current Medicinal Chemistry, 25(40), 5469-5486.

Miller, G. W. (2014). The exposome: A primer. Waltham, MA: Academic Press Elsevier, Inc.

Mirakovski, D., Hadzi-Nikolova, M., Boev, I., Sijakova-Ivanova, T., Zendelska, A., \& Doneva, N. (2018). Sources of urban air pollution in Macedonia - Behind high pollution episodes. International Scientific 
Conference GREDIT, Skopje, Macedonia. Retrieved from http:// eprints.ugd.edu.mk/id/eprint/20866

Morrison, G. C., Weschler, C. J., \& Bekö, G. (2016). Dermal uptake directly from air under transient conditions: Advances in modeling and comparisons with experimental results for human subjects. Indoor Air, 26 (6), 913-924.

Neveu, V., Moussy, A., Rouaix, H., Wedekind, R., Pon, A., Knox, C., ... Scalbert, A. (2017). Exposome-explorer: A manually-curated database on biomarkers of exposure to dietary and environmental factors. Nucleic Acids Research, 45, D979-D984.

Ngoc, L. T. N., Park, D., Lee, Y., \& Lee, Y. C. (2017). Systematic review and meta-analysis of human skin diseases due to particulate matter. International Journal of Environmental Research and Public Health, 14(12), 1458.

Oresajo, C., Pillai, S., Manco, M., Yatskayer, M., \& McDaniel, D. (2012). Antioxidants and the skin: Understanding formulation and efficacy. Dermatologic Therapy, 25(3), 252-259.

Pomés, A. (2002). Intrinsic properties of allergens and environmental exposure as determinants of allergenicity. Allergy, 57(8), 673-679.

Rauma, M., Boman, A., \& Johanson, G. (2013). Predicting the absorption of chemical vapours. Advanced Drug Delivery Reviews, 65, 306-314.

Savitz, D. (2003). Foreward. In M. J. Nieuwenhuijsen (Ed.), Exposure assessment in occupational and environmental epidemology. Oxford, England: Oxford University Press.

Schneider, T., Vermeulen, R., Brouwer, D. H., Cherrie, J. W., Kromhout, H., \& Fogh, C. L. (1999). Conceptual model for assessment of dermal exposure. Journal of Occupational and Environmental Medicine, 56(11), 765-773.

Semple, S. (2004). Dermal exposure to chemicals in the workplace: Just how important is skin absorption? Occupational and Environmental Medicine, 61, 376-382.

Thiele, J. J., Traber, M. G., Podda, M., Tsang, K., Cross, C. E., \& Packer, L. (1997). Ozone depletes tocopherols and tocotrienols topically applied to murine skin. FEBS Letters, 401(2-3), 167-170.

Thiele, J. J., Traber, M. G., Polefka, T. G., Cross, C. E., \& Packer, L. (1997). Ozone-exposure depletes vitamin $\mathrm{E}$ and induces lipid peroxidation in murine stratum corneum. Journal of Investigative Dermatology, 108(5), 753-757.

Thomasen, J. M., Fent, K. W., \& Nylander-French, L. A. (2011). Development of a sampling patch to measure dermal exposures to monomeric and polymeric 1,6-hexamethylene diisocyanate: A pilot study. Journal of Occupational and Environmental Hygiene, 8(12), 709-717.

Trommer, H., \& Neubert, R. H. H. (2006). Overcoming the stratum corneum: The modulation of skin penetration - a review. Skin Pharmacology and Physiology, 19, 106-121.
U.S. Environmental Protection Agency (EPA). (1992). Dermal exposure assessment: Principles and applications (Interim Report), EPA/600/ 8-91/011B. Exposure Assessment Group, Office of Health and Environmental Assessment, US Environmental Protection Agency, Washington, DC.

U.S. Environmental Protection Agency (EPA). (2011). Exposure factors handbook 2011 edition. (EPA/600/R-09/052F). Washington, DC.

U.S. Environmental Protection Agency (EPA). (2017). Particulate matter (PM) pollution. Retrieved from https://www.epa.gov/pm-pollution. Updated May 1, 2017.

United Nations. (2014). World Urbanization Prospects: The 2014 Revision, Highlights (ST/ ESA/SER.A/352). United Nations, Department of Economic and Social Affairs, Population Division.

Weschler, C. J., Bekö, G., Koch, H. M., Salthammer, T., Schripp, T., Toftum, J., \& Clausen, G. (2015). Transdermal uptake of diethyl phthalate and di(n-butyl) phthalate directly from air: Experimental verification. Environmental Health Perspectives, 123, 928-934.

WHO. (2014). Environmental Health Criteria 242. Dermal Exposure. Retrieved from http://www.inchem.org/documents/ehc/ehc/ehc242.pdf.

WHO. (2019). Ten threats to global health in 2019. Retrieved from https:// www.who.int/emergencies/ten-threats-to-global-health-in-2019.

Wild, C. P. (2005). Complementing the genome with an "exposome": The outstanding challenge of environmental exposure measurement in molecular epidemiology. Cancer Epidemiology, Biomarkers \& Prevention, 14(8), 1847-1850.

Wu, C. C., Bao, L. J., Tao, S., \& Zeng, E. Y. (2016). Dermal uptake from airborne organics as an important route of human exposure to $\mathrm{E}$-waste combustion fumes. Environmental Science \& Technology, 50(13), 6599-6605.

Zartarian, V. G., Ott, W. R., \& Duan, N. (2007). Basic concepts and definitions of exposure and dose. In W. R. Ott, A. C. Steinemann, \& L. A. Wallace (Eds.), Exposure Analysis (pp. 33-63). Boca Raton, FL: CRC Press, Taylor \& Francis Group.

How to cite this article: Damevska K, Boev B, Mirakovski D, Petrov A, Darlenski R, Simeonovski V. How to prevent skin damage from air pollution. Part 1: Exposure assessment. Dermatologic Therapy. 2019;e13171. https://doi.org/10.1111/ dth.13171 